\title{
Male Involvement on Skilled Delivery Care Utilization in Mareka Woreda, Southern Ethiopia: A Community Based Cross Sectional Study
}

\author{
Zerihun Tamirat $^{1}$, Tizta Tilahun ${ }^{2}$, Misra Abdulahi ${ }^{2}$ \\ ${ }^{1}$ Dawro Zone health Department, Southern Nations Nationalities Regional State, Tercha, Ethiopia \\ ${ }^{2}$ Department of Population and Family Health, Jimma University Faculty of Public Health and Medical Science, Jimma, Ethiopia
}

Email address:

manjotame@yahoo.com (Z. Tamirat)

\section{To cite this article:}

Zerihun Tamirat, Tizta Tilahun, Misra Abdulahi. Male Involvement on Skilled Delivery Care Utilization in Mareka Woreda, Southern Ethiopia: A Community Based Cross Sectional Study. Science Journal of Public Health. Vol. 3, No. 5, 2015, pp. 699-706.

doi: $10.11648 /$ j.sjph.20150305.26

\begin{abstract}
Back ground: Skilled care for pregnancy and childbirth are the most important issues of reproductive health affected by male partners, however, how male involvement affects maternal health care utilization is lacking. So the study aimed to assess factors for male involvement and skilled delivery care utilization in Mareka woreda. Methods: This cross-sectional study used stratified sampling in Mareka district south east Ethiopia to select 676 couples currently in union who have less than one year old child. A structured questionnaire used to assess male involvement on skilled delivery utilization and associated factors. Multivariate logistic regression analysis was employed in SPSS version 16.0 to analyze independently associated factors. That factor with $\mathrm{p}$ value $<0.05$ was declared as statistically significant at final model. Result: Overall, 32.9\% of women used skilled delivery care and $41.3 \%$ of husbands' involved on skilled delivery care utilization on their recent child birth. Women assisted by skilled birth attendants in their recent delivery were educated AOR=0.01(0.001-0.10), knowledgeable on danger sign AOR= 3.44(1.34-8.79), had favorable attitude for skilled delivery care AOR=2.21(1.11-4.41), and those their husbands' participated on skilled delivery care use AOR=2.35(1.18-4.66). And husbands' who participated on skilled delivery care utilization were educated AOR 1.77(1.13- 2.50)], younger AOR 1.77(1.19-2.62), prefers health facility for delivery AOR 1.85(1.24-2.75) and have had positive perception on importance of skilled delivery care AOR 1.68(1.13, 3.29). CONCLUSION: male involvement on skilled delivery care utilization has a significant effect on women's' use of skilled birth attendants at birth. Finding of our study implies improving awareness of communities on benefit of skilled delivery care and male involvement are needed.
\end{abstract}

Keywords: Skilled Delivery, Mareka Woreda, Male Involvement, Recent Delivery, Utilization

\section{Introduction}

Pregnancy and its related complications, remains one of the major causes of maternal morbidity and mortality worldwide. Globally, over a half million women die every year due to pregnancy and its related causes. Virtually all (87\%) of these maternal deaths occur in low-income countries and sub-Saharan Africa accounting for $56 \%$ of all maternal deaths reported worldwide (1). Maternal death in Ethiopia is persistently high in past two decades despite the improvement in health service coverage representing $30 \%$ of reproductive women death (2).

Around $80 \%$ of maternal deaths worldwide resulted due to direct case (hemorrhage, infection, obstructed labor, unsafe abortion and high blood pressure. If women had access to interventions needed to address complications during pregnancy and childbirth, $74 \%$ of maternal deaths could be avoided (3).

However, only $45 \%$ of births are attended by skilled attendants in SSA and consequently, two million women have died during childbirth since 2010. Ethiopia is in lowest margin in achieving of skilled birth attendance in $\operatorname{SSA}(1,2)$.

Different studies stated that common factors for low utilization of skilled delivery care as factors related with service provision, economic and geographic accessibility, and socio-demographic factors and relatively very few have looked at male partner involvement affect utilization of health services (4).

Man's attitude, knowledge base and ways of reacting influence not only men's health but also women's 
reproductive health (5). Full partnership between men and women is required in both productive and reproductive life (6).

Men, as partners, fathers, husbands, policy makers and community leaders have a critical role to play in safeguarding the health of women during pregnancy and beyond. It is clear that the target of reducing maternal deaths will not be met without the concerted efforts of all involved. Reproductive health interventions that target couples are found to be more effective than those directed to only one (7).

Traditionally, men are kept outside maternal health issues in many societies (5). However, pregnancy care and childbirth are the most important issues of reproductive health affected by male partners. Evidence on how maternal health care utilization is affected by participation of their husbands is lacking in both developing and developed countries (6).

Although men play a key role in their family as the main decision-makers, many studies on determinants of skilled attendants' utilization at delivery excluded men. Therefore, the aim of this study was to answer in what extent male partner involve and affect maternal health service utilization in the study area. In addition to this the study also, examined factors affecting skilled delivery utilization in the study area.

\section{Methods}

\subsection{Study Setting}

Mareka district is located in SNNPR 500KMs south west to Addis Ababa, the capital city of Ethiopia. The district is administratively structured in to 37 kebele, the smallest administrative unit in country, (34 Rural and 3 Urban). The estimated total population of the woreda in 2014 was 143,641(39). The potential health service coverage of district was $80 \%$.

\subsection{Study Design, Participants and Sample Selection}

Community based cross-sectional study was employed in March 2014. Voluntary couples who gave birth within the last 12 months preceding the study were included to study if they are in union, have had less than 12 months old child, and stayed in the study area more than six month. Sample size was estimated by using fisher's single population formula considering confidence level of $95 \%$, power of $80 \%, 5 \%$ degree of precision, male involvement in use of skilled delivery care $68.4 \%$, design effect of 2 and expected non response rate of $5 \%$ in Epi info version 7 . The calculated sample size was 676 couples. Two stages stratified sampling technique used to select study participants. First eight (one urban from 3 and seven rural from 34) kebele were selected randomly by lottery method. Eligible households were selected randomly from the selected kebele proportionally. Since all households in kebele have its own family folder with unique identification number, which is updated in monthly bases for vital events were used to identify eligible household. So identified eligible households has given unique consecutive numbers, making sampling frame, to randomly select calculated sample size. Finally proportionally allocated samples from selected eight kebele were interviewed.

Data was collected through face to face interview using a pre-tested structured questionnaire translated to local language. Six female and six male diploma nurses who were fluent in the local language interviewed women and husband at the same time separately to avoid possible interference of ideas between couples. Before data collection, we have given training for data collectors on data collection technique and the questions so that they can have a common sense on all questions. In order to assure the completeness of questionnaire, the collected was checked daily during data collection.

\subsection{Data Management and Analysis}

Data was checked, cleaned and edited for completeness, outliers and missing values and entered to EpiData version 3.1 and exported to SPSS windows version 16.0 for analysis. Male questionnaire was entered continuously after female's questionnaire making couples response as one case for analysis. Summed scale method was used for analysis of women's attitude and knowledge. Bi-variate and multivariable logistic regression analysis was employed to identify association between outcome and predicator variables. Statistical significance was declared at $\mathrm{P}$ value $<0.05$ on final model. The strength of association was interpreted using the adjusted odds ratio and $95 \% \mathrm{CI}$.

\subsection{Ethical Consideration}

Ethical approval and clearance was obtained from Ethical Review Board (ERB) of Jimma University. Informed consent obtained from the study participants by informing the purpose of the study, its procedure and confidentiality prior to data collection.

\section{Result}

\subsection{Characteristics of Study Participants}

Information was obtained from 635 couples (635 men and their spouses) making a $93.9 \%$ response rate. Five hundred thirty nine $(84.9 \%)$ and $96(15.1 \%)$ of respondents were from rural and urban respectively. The mean age for women was 29.66 with SD of \pm 7.641 ranging from 15 to 49 years. The mean age for husband was 34.09 with SD of \pm 6.763 ranging from 18 to 62 years.

Concerning ethnicity of study participants $629(99.1 \%)$ of women were Dawro and six women were Oromo while the rest $529(83.3 \%)$ of male participants belong to the Dawro and103 (16.2\%) were Oromo ethnic group. Concerning education $19.2 \%$ of husbands have acquired secondary and college education and only $11.0 \%$ women has acquired secondary and college education.

Mothers practicing the Protestant faith were 55\% while $40 \%$ belong to the orthodox Christians. Catholic were 5.0\% of the total respondents. Concerning male partner religion affiliation $52.4 \%, 41.9 \%$ and $5.7 \%$ of husband have practice protestant, orthodox and catholic religion 
respectively. Majority of the mothers and husbands were unemployed $66.5 \%$ and $64.3 \%$ respectively. Reported average household income for family was 606.53 with SD of \pm 670.365 Ethiopian birr. Average family size in households was 5. See table 1 for detail of socio demographic characteristics of the respondents.

Table 1. Socio-demographic characteristics of respondents in Mareka woreda, March 2014.

\begin{tabular}{ll}
\hline Variable & Frequency (\%) \\
\hline Age of women & \\
$<20$ & $61(9.6)$ \\
$20-34$ & $424(66.8)$ \\
$35-49$ & $148(23.3)$ \\
$>49$ & $2(0.3)$ \\
Age of husband & \\
$<20$ & $7(1.1)$ \\
$20-34$ & $331(52.1)$ \\
$35-49$ & $270(42.5)$ \\
$>49$ & $27(4.3)$ \\
Educational status of women & \\
Illiterate & $289(45.7)$ \\
Primary education & $276(43.3)$ \\
Secondary \& above & $70(11)$ \\
Educational status of husband & \\
Illiterate & $201(31.7)$ \\
Primary education & $312(49.1)$ \\
Secondary \& above & $122(19.2)$ \\
Work status of women & \\
Housewife & $422(66.5)$ \\
Farmers & $96(15.1)$ \\
Merchant & $67(10.5)$ \\
Civil servant & $28(4.4)$ \\
Student & $10(1.6)$ \\
Daily labourers & $9(1.4)$ \\
Others & $3(0.5)$ \\
Fork status of husband & \\
Merchant & $408(64.2)$ \\
Civil servant & $123(19.4)$ \\
Student & $41(6.5)$ \\
Daily laborers & $19(2.8)$ \\
Others & $16(2.5)$ \\
\hline &
\end{tabular}

\subsection{Obstetric History of the Respondents}

For $97(15.3 \%)$ mothers the last pregnancy was their first and $168(26.5 \%)$ of them had 5 to 9 pregnancies. About $83.5 \%$ of women have more than one living child. The average number of children for a woman was 3. From total respondents $20.8 \%, 4.1$ $\%$ and $16.4 \%$ had history of abortion, still birth and neonatal death respectively. One hundred forty one $(22.2 \%)$ women's current pregnancy was unplanned. Overall, 561(88.3\%) of women had attended antenatal care (ANC) at least once. Of those attended ANC, 232(45.4\%) started within first trimester and $274(54.5 \%)$ had sufficient visit, four or more visits recommended by WHO, on their most recent pregnancy.

Home deliveries were $356(56.1 \%)$, while the rest $279(43.9 \%)$ were conducted in health institution. Those who gave birth in health facility $(32.9 \%)$ in health center and hospital were assisted by skilled birth attendants but the rest $70(11 \%)$ delivered in health post assisted by community health extension workers.
Table 2. Obstetric history of women respondents in Mareka woreda, March 2014.

\begin{tabular}{lll}
\hline Variables & Frequency & $\%$ \\
\hline Gravidity $(\mathrm{n}=635)$ & & \\
1 & 97 & 15.3 \\
$2-4$ & 370 & 58.2 \\
$>5$ & 168 & 26.5 \\
Living children $(\mathrm{n}=635)$ & & \\
1 & 105 & 16.5 \\
$2-4$ & 384 & 60.5 \\
$>5$ & 146 & 23.0 \\
No. of ANC visit $(\mathrm{n}=561)$ & & \\
$1-3$ times & 229 & 40.9 \\
4 times and above & 274 & 48.8 \\
Do Not remember** & 58 & 10.3 \\
Started ANC visit $(\mathrm{n}=561)$ & & \\
$1^{\text {st }}$ trimester & 232 & 36.6 \\
$2^{\text {nd }}$ trimester & 182 & 28.7 \\
$3^{\text {rd }}$ trimester & 97 & 15.4 \\
Don't remember** & 50 & 7.7 \\
\hline
\end{tabular}

(**) Missing and mothers not remembered number of ANC visit

Regarding women's attitude toward skilled delivery service utilization, $325(51.2 \%)$ of the study participants had favorable attitude on skilled delivery service whereas 568(89.6\%) of them had unfavorable responses for the question women should plan the way how a woman should get to health facility to give birth and $326(51.4 \%)$ for effect of delivery complication on new born.

Concerning knowledge level of the women, 339(53.4\%), $390(61.4 \%)$ and 333(52.4\%) were knowledgeable on danger sign related with pregnancy, danger sign related with labor and delivery, and benefits of maternal health service for mother and newborn during pregnancy and delivery respectively.

Overall, 261(41.1\%) of women were knowledgeable on pregnancy, labor and delivery related danger signs and benefit of maternal health services provided during pregnancy, labor and delivery.

According to the study, 408(64.7\%) of men were aware either their wife have attended ANC service or not and $575(90.6 \%)$ reported that they had discussed on delivery related issue with their wife in their recent pregnancy.

One hundred forty five $(33.4 \%)$ husband were planned health facility (health center or Hospital), 108(24.9\%) health post, $93(21.4 \%)$ their home, and $88(20.3 \%)$ mother in-law's' home for their recent child birth. Two hundred sixty eight $(42.4 \%)$ of male preferred skilled attendants at birth whereas the rest preferred non skilled attendants to assist their wife on recent delivery. Among husbands who made prior arrangement for delivery $42.2 \%$ identified transportation, 84.7 $\%$ save money and $41.7 \%$ identified skilled provider for delivery assistance.

The study showed that 196 (44.1\%) of men involved on skilled delivery care on recent child birth, 273(43\%) of men made joint decision on place of delivery, and $448(70.5 \%)$ of men made prior arrangement for delivery. Regarding perception of males on the benefit of delivering on health facility, $326(51.3 \%)$ has positive perception on benefit of skilled attendant at delivery where as the rest 309(48.7\%) 
responded facility delivery is either less important or the same as home delivery.

Bivariate analysis shows education of husband and women, women pregnancy order below three, early start of ANC visit, women's good knowledge on danger sign, favorable attitude towards skilled delivery care and husbands' involvement has significant association with skilled delivery care utilization (Table 3\&4).

Table 3. Bivariate analysis of factors affecting use of skilled delivery among recently delivered women in Mareka ( $n=635)$.

\begin{tabular}{|c|c|c|c|c|}
\hline \multirow{2}{*}{ Variables } & \multicolumn{2}{|c|}{ Used skilled delivery } & \multirow{2}{*}{ OR $95 \%$ CI } & \multirow{2}{*}{ P-value } \\
\hline & Yes (209) & No (424) & & \\
\hline \multicolumn{5}{|c|}{ Educational status of husbands } \\
\hline Primary and below & $131(20.6)$ & $382(60.1)$ & $0.19(0.13-0.29)$ & 0.001 \\
\hline Post primary & $78(12.3)$ & $44(7)$ & 1.0 & \\
\hline \multicolumn{5}{|c|}{ Educational status of wife } \\
\hline Primary and below & $143(22.5)$ & $422(66.5)$ & $0.02(0.07-0.10)$ & 0.01 \\
\hline Post primary & $66(10.4)$ & $4(0.6)$ & 1.0 & \\
\hline \multicolumn{5}{|l|}{ Number of pregnancy } \\
\hline 1-3 pregnancy & $141(22.2)$ & $216(34.0)$ & $2.01(1.42-2.85)$ & 0.008 \\
\hline 4 and above & $68(10.7)$ & $210(33.1)$ & 1.0 & \\
\hline \multicolumn{5}{|l|}{ Pregnancy planned } \\
\hline Yes & $179(28.2)$ & $315(49.6)$ & $2.13(1.35-3.27)$ & 0.004 \\
\hline No & $30(4.7)$ & $111(17.5)$ & 1.0 & \\
\hline \multicolumn{5}{|l|}{ Initiated ANC service } \\
\hline Early & $110(21.5)$ & $122(23.9)$ & $2.64(1.82-3.84)$ & 0.0001 \\
\hline Late & $71(13.9)$ & $208(40.7)$ & 1.0 & \\
\hline \multicolumn{5}{|c|}{ Favourable attitude to SBA } \\
\hline Favourable & $143(22.5)$ & $182(28.7)$ & $2.91(2.05-4.12)$ & 0.0001 \\
\hline Unfavourable & $66(10.4)$ & $244(38.4)$ & 1.0 & \\
\hline \multicolumn{5}{|c|}{ Knowledgeable on skilled delivery care } \\
\hline Yes & $136(21.4)$ & $125(19.7)$ & $4.48(3.15-6.38)$ & 0.0001 \\
\hline No & $73(11.5)$ & $301(47.4)$ & 1.0 & \\
\hline \multicolumn{5}{|c|}{ Male involved on skilled delivery care } \\
\hline Yes & $108(24.4)$ & $88(19.9)$ & $2.76(1.87-4.08)$ & 0.0001 \\
\hline No & $76(17.2)$ & $172(38.8)$ & 1.0 & \\
\hline
\end{tabular}

Table 4. Bivariate analysis of factors affecting male involvement on skilled delivery among women's had birth one year prior study in Mareka woreda. ( $n=444)$.

\begin{tabular}{|c|c|c|c|c|}
\hline \multirow{2}{*}{ Variables } & \multicolumn{2}{|c|}{ Male involvement } & \multirow{2}{*}{ OR 95\% CI } & \multirow{2}{*}{ P-value } \\
\hline & Yes $(\%)$ & No $(\%)$ & & \\
\hline \multicolumn{5}{|l|}{ Age of husband } \\
\hline Below 35 & $115(25.9)$ & $105(23.6)$ & $1.93(1.32-2.83)$ & 0.001 \\
\hline Above 35 & $81(18.2)$ & $143(32.2)$ & 1.0 & \\
\hline \multicolumn{5}{|l|}{ Mothers occupation } \\
\hline House wife & $106(23.9)$ & $169(38.1)$ & $0.55(0.37-0.81)$ & 0.002 \\
\hline Other than house wife & $90(20.3)$ & $79(17.8)$ & 1.0 & \\
\hline \multicolumn{5}{|c|}{ Maternal educational status } \\
\hline Post primary & $38(8.6)$ & $21(4.7)$ & $2.6(1.47-4.59)$ & 0.001 \\
\hline Primary and below & $158(35.6)$ & $227(51.7)$ & 1.0 & \\
\hline \multicolumn{5}{|c|}{ Husbands educational status } \\
\hline Post primary & $55(12.4)$ & $37(8.3)$ & $2.22(1.39-3.55)$ & 0.001 \\
\hline Primary and below & $146(35.8)$ & $182(57.8)$ & 1.0 & \\
\hline \multicolumn{5}{|c|}{ Husband perceive delivery in health facility is important } \\
\hline Yes & $140(34.3)$ & $108(26.5)$ & $2.16(1.44-3.24)$ & 0.0001 \\
\hline No & $60(14.7)$ & $100(24.5)$ & 1.0 & \\
\hline \multicolumn{5}{|c|}{ Husband preferred skilled assistance for delivery } \\
\hline Yes & $100(22.5)$ & $89(20)$ & $1.86(1.27-2.73)$ & 0.0001 \\
\hline No & $96(21.6)$ & $159(35.8)$ & 1.0 & \\
\hline
\end{tabular}

In multivariable logistic regression analysis, factors that remained significant to affect skilled attendant use by women at delivery were husband age below 35 years [AOR 1.77, 95\% CI: 1.9-2.62], husband post primary educational level [AOR 1.77, 95\% CI: 1.13-2.50], husbands positive perception on skilled care [AOR 1.68, 95\% CI: 1.13-2.5] and husband preference of skilled attendant [AOR 1.85, 95\% CI: 1.24-2.75]. In another hand factors that determine male involvement on skilled delivery care were husbands' positive perception on skilled care [AOR 1.68, 95\% CI: 1.13-2.50], educational level of husband [AOR 1.77, 95\% CI: 1.13-2.50], husbands preference for skilled assistant at delivery [AOR 1.85, 95\% CI: 
1.24-2.75] and husbands age below 35 years [AOR 1.77, 95\% CI: 1.19-2.62].

Table 5. Multivariable logistic analysis of factors associated with use of skilled delivery care by women who gave birth 12 months prior to study in Mareka district, $2014(n=635)$.

\begin{tabular}{|c|c|c|c|c|}
\hline \multirow{2}{*}{ Variables } & \multicolumn{2}{|c|}{ Used skilled delivery } & \multirow{2}{*}{ COR } & \multirow{2}{*}{ AOR95\%CI } \\
\hline & Yes & No & & \\
\hline \multicolumn{5}{|c|}{ Women education level } \\
\hline Primary and below & $143(22.5)$ & $422(66.5)$ & 0.02 & $0.01(0.001-0.10)^{* * *}$ \\
\hline Post primary & $66(10.4)$ & $4(0.6)$ & 1.0 & 1.0 \\
\hline \multicolumn{5}{|c|}{ Husband education level } \\
\hline Primary and below & $131(20.6)$ & $382(60.1)$ & 0.19 & $0.27(0.12-0.66)^{*}$ \\
\hline Post primary & $78(12.3)$ & $44(7)$ & 1.0 & 1.0 \\
\hline \multicolumn{5}{|l|}{ Number of pregnancy } \\
\hline 1-3 pregnancy & $141(22.2)$ & $216(34.0)$ & 2.01 & $2.65(1.31-5.37)^{* *}$ \\
\hline Above $>3$ pregnancy & $68(10.7)$ & $210(33.1)$ & 1.0 & 1.0 \\
\hline \multicolumn{5}{|c|}{ Knowledge of women skilled delivery care } \\
\hline Knowledgeable & $136(21.4)$ & $125(19.7)$ & 5.28 & $3.44(1.34-8.79)^{* *}$ \\
\hline Not knowledgeable & $73(11.5)$ & $301(47.4)$ & 1.0 & 1.0 \\
\hline \multicolumn{5}{|c|}{ Attitude of women towards SBA } \\
\hline Favourable & $143(22.5)$ & $182(28.7)$ & 2.91 & $2.21(1.11-4.41)^{*}$ \\
\hline Unfavourable & $66(10.4)$ & $244(38.4)$ & 1.0 & 1.0 \\
\hline \multicolumn{5}{|c|}{ Male involvement on skilled delivery care } \\
\hline Yes & $108(24.4)$ & $88(19.9)$ & 2.76 & $2.35(1.18-4.66)^{*}$ \\
\hline No & $76(17.2)$ & $172(38.8)$ & 1.0 & 1.0 \\
\hline
\end{tabular}

(*) p value significant $<0.05,(* *) \mathrm{p}$ value significant $<0.01$ and $(* * *)$ p value significant $<0.0001$

Table 6. Multivariable analysis of factors associated with men involvement on skilled care service utilization in Mareka district, 2014 ( $n=311$ ).

\begin{tabular}{|c|c|c|c|c|}
\hline \multirow{2}{*}{ Variables } & \multicolumn{2}{|c|}{ Male involved } & \multirow{2}{*}{ COR } & \multirow{2}{*}{ AOR 95\% CI } \\
\hline & Yes & No & & \\
\hline \multicolumn{5}{|c|}{ Husbands educational status } \\
\hline Post primary & $55(12.4)$ & $37(8.3)$ & 2.22 & $1.77(1.13-2.50)^{* *}$ \\
\hline Primary and below & $146(35.8)$ & $182(57.8)$ & 1.0 & 1.0 \\
\hline \multicolumn{5}{|l|}{ Age of husband } \\
\hline Less than $35 y r s$. & $115(25.9)$ & $105(23.6)$ & 1.93 & $1.77(1.19-2.62)^{*}$ \\
\hline \multicolumn{5}{|c|}{ Husband prefers skilled assistance } \\
\hline Yes & $100(22.5)$ & $89(20)$ & 1.86 & $1.85(1.24-2.75)^{* *}$ \\
\hline No & $96(21.6)$ & $159(35.8)$ & 1.0 & 1.0 \\
\hline \multicolumn{5}{|c|}{ Husband perceive delivering in health facility is important } \\
\hline Yes & $140(34.3)$ & $108(26.5)$ & 1.82 & $1.68(1.13-2.50)^{* * *}$ \\
\hline No & $60(14.7)$ & $100(24.5)$ & 1.0 & 1.0 \\
\hline
\end{tabular}

(*) p value significant $<0.05,(* *)$ p value significant $<0.01$ and $(* * *)$ p value significant $<0.0001$

\section{Discussion}

As hypothesized both husband and wife factor affect maternal health service use by the women, although wives' factors remained to be more predictive variable for their current service use. Accordingly women who used skilled birth attendants in their recent delivery were educated, knowledgeable on danger sign, who had favorable attitude on skilled delivery care and those whose husbands' participated on skilled delivery care.

Home delivery is still a norm in many developing countries; maternal mortality tends to be highest where this is the case in the study area. In this study, only $32.9 \%$ of births took place at health facility by the help of skilled attendants. This finding is not in agreement with the previous studies from Dodota (22\%), Arsi (17\%), Sekela (13.5\%), Munisa (12.3\%), and EDHS 2011 (11\%) (2,4, 8-10). The difference may be related with recently introduced new strategy like health development army, which creates an opportunity to access information on maternal health services and promote community involvement to support women during labor and delivery, has a great impact on recent skilled delivery status. In addition to this specific health programs like provision of ambulance for every district may work to the advantage of the current status. However the use of skilled delivery in this study is lower than the finding from Wayu town, Western Ethiopia which is $47.2 \%$ of women delivered their last child birth in health facility (11).The difference may be attributed due to the residential variation of study participants. 
Results of this study revealed that use of skilled birth attendants were significantly associated with the level of education. There is strong evidence that educated couples use skilled delivery care than uneducated ones. Most maternal and child health studies conducted in developing countries strongly agree with this findings $(8,12-15)$. This may be the fact that, education is likely to enhance female autonomy and communication with partners so that women develop greater confidence and capacity to make decisions about their own health.

The number of previous pregnancies is an important determinant for utilization of skilled delivery services in this study and it is consistent with study done in Ethiopia and India $(16,17)$. The number of pregnancy increase likelihood of using the skilled delivery services in the study area. Lower utilization of maternal care services among multi-parious women could be due to time and resource constraints faced by those with large families, and greater experience of higher parity. Multi-parious women on the other hand, tend to believe that modern health care is not as necessary due to experiences and accumulated knowledge from previous pregnancies and births, therefore, they had have more confidence about pregnancy and childbirth and thus may give less importance to skilled delivery $(4,10,18)$.

Women's attitude towards maternal health services and knowledge on pregnancy related danger sign were found to affect maternal health care use here and elsewhere. There was a higher probability of utilization among mothers who showed favorable attitude and had good knowledge. The finding is similar to previous studies in Ethiopia and other developing countries. The uses of skilled attendant were significantly higher among women's who were knowledgeable and showed favorable attitude to skilled care at birth $(10,12,19-21)$.

In this study $41.1 \%$ of women have good knowledge on the acceptable danger signs of pregnancy and delivery. Respondents' knowledge of potential danger signs of pregnancy is an important factor for use of skilled delivery services $(8,12)$. Women who experienced concern about any health problems were more likely to be user. This indicates that understanding of the nature and the importance of delivery care services. Reports from Bangladesh and India came-up with similar findings $(9,22)$.

Our study found that women whose husband involved on skilled delivery care were almost two times more likely to use skilled attendant at birth than those whose husband not involved. The finding implies that men who involved were educated about the importance of skilled birth attendance. This finding reinforces other studies that reported women were more likely to have better outcomes when their husbands involved in maternal health care by supporting their wives during pregnancy (20). Also studies in India and Nepal have found that women whose husbands show concern in pregnancy were more likely to utilize reproductive health services $(21,24)$.

The study revealed that the proportion of male involvement on skilled delivery care was relatively low at $34.6 \%$. Only $32.7 \%$ of husbands' planned health facility for delivery, $52.4 \%$ made joint decision for skilled delivery care and $43.2 \%$ made prior arrangement for delivery. This finding is inconsistent with study done in northern Uganda where $48 \%$ of male involved on skilled delivery care (25). The study finding from Nigeria showed $56 \%$ of womens' final decision on location of birth was taken in consultation with spouse (24). This level of variation of male involvement may be attributed to gender roles and socio-cultural variation among countries.

From study finding, low education level of man was significant factor contributed for low male involvement. The finding of this study is similar to the studies carried out in Busia district of Kenya and Omoro County district of Uganda in which un-educated men were found to be less likely to participate in reproductive health of their partner $(20,25)$. Study suggested uneducated men tend to hold on to traditional belief which greatly impair inter spousal communication leading to low male involvement in reproductive health (7).

In this study younger men were involved two times more likely on skilled delivery care than older ones. The observed higher participation among younger men in this study is similar to the findings from Nigerian (26). This could be due to the fact that younger men are more adventurous and likely to challenge cultural norms. In addition to this they may have better chance of education which is known to positively influence health seeking behavior.

Husbands' positive perception on maternal health service utilization was associated with increased participation. Our finding shows male who perceived delivery in health facility is important for mother and new born were two times more likely to participate on maternity care than those who perceived it has no importance. This result is consistent with finding from Uganda where husband positive perception on benefit of maternity care on prevention of pregnancy related complication was resulted in high level participation of male (25). Studies have shown that when men knows the danger signs of pregnancy and delivery, they may act as life-saving agents, ensuring that their wives got appropriate attention in obstetric emergencies (7).

\section{Strength and Limitation of the Study}

Strength of the Study: The study is community based study, used primary data from both male and female partner using interviewer administered questioner prepared in local language. To minimize recall bias data collected from women who gave birth 12 months prior to the study and their partners. Also couples interviewed separately by male and female interviewer at the same time to avoid possible interference of ideas between respondents.

Limitations: The finding might be subjected to social desirability bias because the finding was based on self-reported responses of couples.

\section{Conclusion}

Skilled delivery care use was low at $32.9 \%$ compared to $60 \%$ national target. Factors determined skilled delivery care use in 
the area was education level of couple, birth order, knowledge and attitude of women on skilled delivery care and husbands' involvement on skilled delivery care.

Although male involvements on skilled care have a significant effect on use of skilled care, only $34.6 \%$ of male partner participated on skilled attendant at birth in study area. Men who were educated, younger, prefers skilled birth attendant, and positively perceive on benefit of skilled care for mother and newborn were demonstrated a greater participation on skilled care utilization.

Therefore for improvement of skilled delivery care utilization, Regional health bureau should take steps to raise awareness on the importance and benefits of skilled delivery care and male involvement on skilled care to get support from male partners. On other hand local health authority and health unit should raise awareness of community and families through designing the way how men will be invited for ANC with their wife, using community health workers and community leaders in reaching out to men and encouraging their involvement on skilled delivery care services.

Also further studies to establish knowledge and attitude of male on maternal health services would strengthen strategies for improving male involvement in maternal health services utilization.

\section{Acknowledgements}

Our special thanks to Jimma University for financial support. We thank the respondents for their time and information that have enabled us to understand male involvement on skilled delivery care and associated factors for use of skilled care at birth. We also extend our appreciation to district health office and health extension workers for their cooperation, facilitation and provision of relevant information.

\section{Author's Contributions}

Zerihun Tamirat, have made substantial contributions to beginning and design, collection of data, analysis and interpretation of data and in drafting the manuscripts and correcting the comment given by the advisors.

Tizta Tilahun, involved in revising the research paper and the manuscript for important intellectual context and approval of the final version to be published and participated in its design and coordination.

Misra Abdulahi, involved in revising the research paper and the manuscript critically for important intellectual context and approval of the final version to be published and participated in its design and coordination.

\section{References}

[1] UN. The Millennium Development Goals Report 2013. New York; 2013.

[2] CSA and ICF International Calverton. Ethiopia Demographic and health survey 2011. Addis Ababa, Ethiopia; 2012.
[3] WHO. Making pregnancy safer: the critical role of the skilled attendant: a joint statement by WHO, ICM and FIGO. Geneva, Switz. WHO. 2004.

[4] Fikre AA, Demissie M. Prevalence of institutional delivery and associated factors in Dodota Woreda (district), Oromia regional state, Ethiopia. Reproductive Health; 2012 Jan;9(1):33.

[5] UNFPA. Men at work. World Population Day document. Retrieved September 10. [Internet]. 2007. Available from: http://www.unfpa.org.

[6] UNFPA. The Fourth World Conference on Women,Beijing Declaration and Platform for Action. 1995. p. 1-132.

[7] Davis J, Luchters S, Holmes W. Men and maternal and newborn health. 2013;(February).

[8] Abera M, Belachew T. Pridicators of safe delivery service utilization in Arsi Zone, South-East Ethiopia. Ethiop. J. Heal. Sci. $2011 ; 12$.

[9] Amano A, Gebeyehu A, Birhanu Z. Institutional delivery service utilization in Munisa Woreda, South East Ethiopia: a community based cross-sectional study. BMC Pregnancy and Childbirth; 2012;12(1):1.

[10] Teferra A. Associated factors for use of skilled delivery among mothers who gave birth in the last 12 months in Sekela District, North West of Ethiopia: A community-based cross sectional study. BMC Pregnancy Childbirth. 2012;12(74):1-11.

[11] Kababa Temesgen Danusa, Gemechu Kejela Jilo. Safe Delivery Service Utilization Five Years Preceding the Survey in Wayu Town, Western Ethiopia. Science Journal of Public Health.Vol. 3, No. 1, 2015, pp. 87-92. doi: $10.11648 /$ j.sjph.20150301.25

[12] Awoke W, Muhammed J, Abeje G. Institutional delivery service utilization in Woldia, Ethiopia. Sci. J. Public Heal. 2013;1(1):18-23.

[13] Bhatta DN. Involvement of males in antenatal care , birth preparedness, exclusive breast feeding and immunizations for children in Kathmandu , Nepal. BMC Pregnancy and Childbirth; 2013;13(1):1.

[14] Dahal R. Factors Influencing the Choice of Place of Delivery among Women in Eastern Rural Nepal. Int. J. Matern. child Heal. 2013;1(2):30-7.

[15] Worku AG, Yalew AW, Afework MF. Factors affecting utilization of skilled maternal care in Northwest Ethiopia: a multilevel analysis. BMC Int. Health Hum. Rights. 2013 Jan;13:20.

[16] Gistane Ayele, Maralign Tilahune, Behailu Merdikyos,Worku Animaw, Wondimagegn Taye. Prevalence and Associated Factors of Home Delivery in Arbaminch Zuria District, Southern Ethiopia: Community Based Cross Sectional Study. Science Journal of Public Health. Vol. 3, No. 1, 2015, pp. 6-9. doi: $10.11648 /$ j.sjph.20150301.12

[17] Sugathan K, Mishra V, Retherford R. Promoting institutional deliveries in rural India: The role of antenatal-care services. $2001 ;(20)$.

[18] Rakibul Islam. Maternal Morbidity and Mortality among Indigenous People in Bangladesh: A Study of the Mru Community Maternal Morbidity and Mortality among Indigenous People in Bangladesh: A Study of the Mru Community 
[19] Birmeta K, Dibaba Y, Woldeyohannes D. Determinants of maternal health care utilization in Holeta town , central Ethiopia. BMC Health Services Research; 2013;13(1):1.

[20] Nanjala M, Wamalwa D. Determinants of Male Partner Involvement in Promoting Deliveries by Skilled Attendants in Busia, Kenya. 2012;4(2):60-7.

[21] Wanjira C, Mwangi M. Delivery practices and associated factors among mothers seeking child welfare services in selected health facilities in Nyandarua South District, Kenya. BioMed Central Ltd; 2011;11(1):360.

[22] Hazarika I. Women 's Reproductive Health in Slum Populations in India : Evidence From NFHS-3. J. Urban Heal. 2009;87(2):264-77.
[23] Thapa DK. Woman' s autonomy and husband 's involvement in maternal health. 2012;

[24] Turyakira E, Pettersson KO. Influence of Birth Preparedness , Decision-Making on Location of Birth and Assistance by Skilled Birth Attendants among Women in South-Western Uganda. 2012;7(4).

[25] Tweheyo R, Konde-lule J, Tumwesigye NM, Sekandi JN. Male partner attendance of skilled antenatal care in peri-urban Gulu district, Northern Uganda. 2010;

[26] Iliyasu Z, Abubakar IS, Galadanci HS, Aliyu MH. Birth Preparedness, Complication Readiness and Fathers' Participation in Maternity Care in a Northern Nigerian Community. 2010;14(1):21-32. 